\title{
New Current-Mode Bandpass Filters Using Three Single-Output ICCIIs
}

\begin{abstract}
Ahmed M. Soliman
Faculty of Engineering, Cairo University, Giza 12613, Egypt

Received 16 May 2007; Accepted 18 September 2007

Recommended by Abu Khari A'ain

New current-mode bandpass filters using three single outputs inverting second generation current conveyors (ICCII) are introduced. The first circuit uses two ICCII+ and one ICCII-, and realizes an inverting bandpass response. This circuit has one floating resistor and no independent gain control. The second circuit uses three ICCII- and realizes a noninverting bandpass response. The third circuit uses three ICCII+ and realizes also a noninverting bandpass response. The second and third circuits employ four grounded resistors and two grounded capacitors and have independent control on $Q$ and on the center frequency gain by varying a single grounded resistor. Spice simulation results using $0.5 \mathrm{um}$ CMOS transistors are included to support the theoretical analysis.
\end{abstract}

Copyright (c) 2007 Ahmed M. Soliman. This is an open access article distributed under the Creative Commons Attribution License, which permits unrestricted use, distribution, and reproduction in any medium, provided the original work is properly cited.

\section{INTRODUCTION}

The differential voltage current conveyor (DVCC) having a balanced output current was introduced in [1]. The DVCC realizes the inverting CCII+ (ICII+) or the inverting CCII(ICCII-) as special cases.

The symbolic representation of the ICCII is shown in Figure 1(a). The relation between terminal voltages and currents is given by the following matrix equation [1]:

$$
\left[\begin{array}{c}
I_{Y} \\
V_{X} \\
I_{Z}
\end{array}\right]=\left[\begin{array}{ccc}
0 & 0 & 0 \\
-1 & 0 & 0 \\
0 & \pm 1 & 0
\end{array}\right]\left[\begin{array}{c}
V_{Y} \\
I_{X} \\
V_{Z}
\end{array}\right] .
$$

The voltage at terminal $X$ is the inversion of the voltage at terminal $Y$. The current at terminal $Z$ follows the current at terminal $X$ in magnitude. In (1), the \pm 1 specifies the type of the current conveyor (ICCII+ or ICCII-). By convention, the positive sign is taken to mean that the currents at the $X$ and $Z$ terminals are both flowing inwards to the conveyor. Figure 1(b) represents the CMOS circuit of the ICCII+ as special case from the DVCC given in $[1,2]$. Figure 1(c) represents the CMOS circuit of the ICCII- given in [3], which is based on using the floating current source [4] to avoid the use of current mirrors in transferring current from port $X$ to port $Z$ of the conveyor.

Current-mode filters have been introduced in the literature using two-output CCIIs $[5,6]$ or single-output CCIIs
$[7,8]$. The circuit reported in [7] uses five CCII+ and has two floating resistors, and the circuit in [8] has the advantage that all passive elements are grounded and it uses three CCII+ and one CCII-.

A current-mode filter which uses three single output ICCII+ was given in [9]. The circuit suffers however from having all resistors and capacitors being floating, besides, the capacitors are connected to the $X$ terminals of the ICCII+ which limits the operating frequency of the circuit. Also there is no independent control on the gain or on the filter pole $Q$ since the filter reported in [9] uses the minimum number of passive components, namely, two resistors and two capacitors.

In this paper all the disadvantages mentioned above will be avoided by introducing new current-mode bandpass filters using three ICCII+ or three ICCII-. Two of the proposed circuits employ four grounded resistors and two grounded capacitors and has independent control on $Q$ and on the center frequency gain. It should be noted that the presented filters exhibit a bandpass response at their high impedance outputs, whereas the filter in [9] produces all the three filter responses at high-impedance outputs.

\section{THE FIRST-PROPOSED BANDPASS FILTER}

Figure 2 represents the block diagram of the proposed current-mode filter. The block diagram is a modified version from the Tow-Thomas well-known block diagram $[10,11]$ 


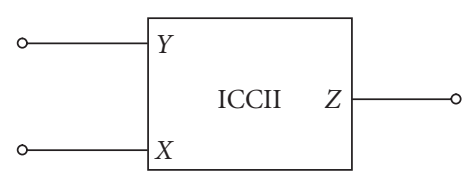

(a) The ICCII symbol

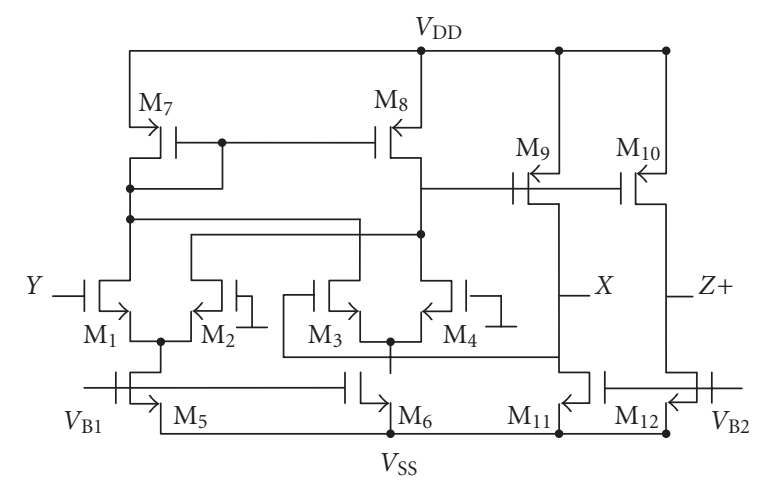

(b) The CMOS circuit of the ICCII+ [1]

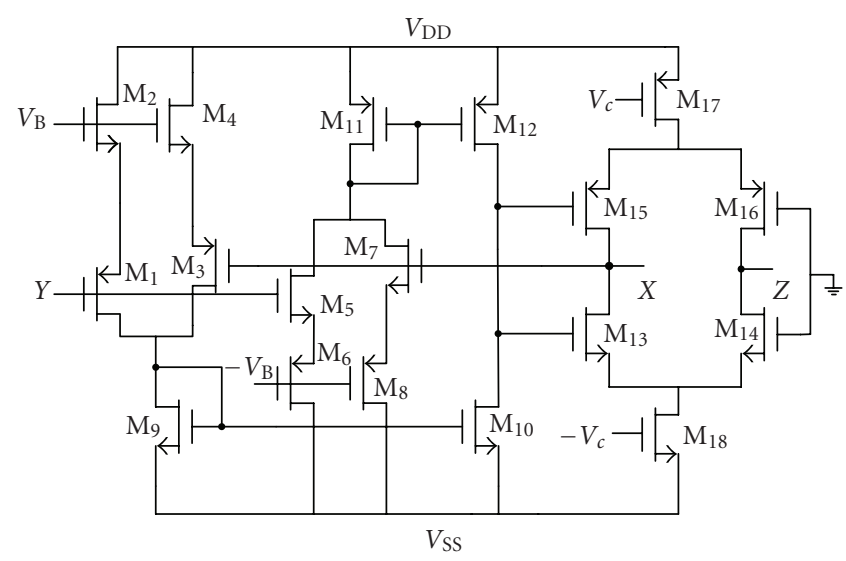

(c) The CMOS circuit of the ICCII- [3]

Figure 1

TABle 1: Transistor aspect ratios of the ICCII- are shown in Figure 1(c).

\begin{tabular}{ll}
\hline Transistor & $W(\mu \mathrm{m}) / \mathrm{L}(\mu \mathrm{m})$ \\
\hline $\mathrm{M}_{1}, \mathrm{M}_{2}, \mathrm{M}_{3}, \mathrm{M}_{4}, \mathrm{M}_{5}, \mathrm{M}_{6}, \mathrm{M}_{7}, \mathrm{M}_{8}$ & $50 / 1.5$ \\
$\mathrm{M}_{9}, \mathrm{M}_{10}$ & $12.5 / 1.5$ \\
$\mathrm{M}_{11}, \mathrm{M}_{12}$ & $37.5 / 1.5$ \\
$\mathrm{M}_{13}, \mathrm{M}_{14}$ & $25 / 0.5$ \\
$\mathrm{M}_{15}, \mathrm{M}_{16}$ & $50 / 0.5$ \\
$\mathrm{M}_{17}$ & $82.5 / 1.5$ \\
$\mathrm{M}_{18}$ & $39.5 / 1.5$ \\
\hline
\end{tabular}

with a current to voltage lossy integrator in the forward path and a lossless integrator in the feedback path.

Figure 3(a) represents the first proposed current-mode bandpass filter circuit using three ICCII with two grounded capacitors and three resistors one of them is floating. The circuit block diagram is shown in Figure 3(b).
TABLE 2: Transistor aspect ratios of the ICCII+ are shown in Figure 1(b).

\begin{tabular}{ll}
\hline Transistor & $W(\mu \mathrm{m}) / \mathrm{L}(\mu \mathrm{m})$ \\
\hline $\mathrm{M}_{1}, \mathrm{M}_{2}, \mathrm{M}_{3}, \mathrm{M}_{4}$ & $25 / 0.5$ \\
$\mathrm{M}_{5}, \mathrm{M}_{6}$ & $8 / 0.5$ \\
$\mathrm{M}_{7}, \mathrm{M}_{8}$ & $10 / 0.5$ \\
$\mathrm{M}_{9}, \mathrm{M}_{10}$ & $40 / 2$ \\
$\mathrm{M}_{11}, \mathrm{M}_{12}$ & $20 / 2.5$ \\
\hline
\end{tabular}

The current transfer function of the filter is given by

$$
\frac{I_{\mathrm{BP}}}{I_{i}}=\frac{-s / C_{2} R_{2}}{s^{2}+s / C_{2} R_{3}+1 / C_{1} C_{2} R_{1} R_{2}} .
$$

The $\omega_{o}$ and $Q$ are given by

$$
\omega_{o}=\frac{1}{\sqrt{C_{1} C_{2} R_{1} R_{2}}}, \quad Q=R_{3} \sqrt{\frac{C_{2}}{C_{1} R_{1} R_{2}}} .
$$

The magnitude of the center frequency gain is given by

$$
G=\frac{R_{3}}{R_{2}} .
$$

It is seen that $R_{3}$ controls $Q$ of the filter without affecting $\omega_{o}$. However, there is no independent control on the gain.

The $Z$ polarities of the first and second ICCII must be opposite to each other whereas the third one polarity is arbitrary; therefore, four possible sign combinations can be obtained. The circuit however cannot employ three identical ICCII which is one of its disadvantages; besides, $R_{2}$ is floating. The second proposed circuit overcomes these limitations as described in the next section.

\section{THE SECOND-PROPOSED BANDPASS FILTER}

Figure 4(a) represents the second proposed current-mode bandpass filter using three ICCII- with all grounded passive elements. The circuit block diagram is shown in Figure 4(b).

The current transfer function of the filter is given by

$$
\frac{I_{\mathrm{BP}}}{I_{i}}=\frac{s / C_{2} R_{4}}{s^{2}+s / C_{2} R_{3}+1 / / C_{1} C_{2} R_{1} R_{2}} .
$$

The $\omega_{o}$ and $Q$ are the same as given by (3) and the gain is given by

$$
G=\frac{R_{3}}{R_{4}} .
$$

For a specified center frequency gains $G, \omega_{o}$, and $Q$, the design equations are given by

$$
\begin{aligned}
& C_{1}=C_{2}=C, \quad R_{3}=R_{1} Q, \\
& R_{1}=R_{2}=\frac{1}{\omega_{o} C}, \quad R_{4}=\frac{R_{3}}{G} .
\end{aligned}
$$

The circuit has very low sensitivities to all circuit components. 


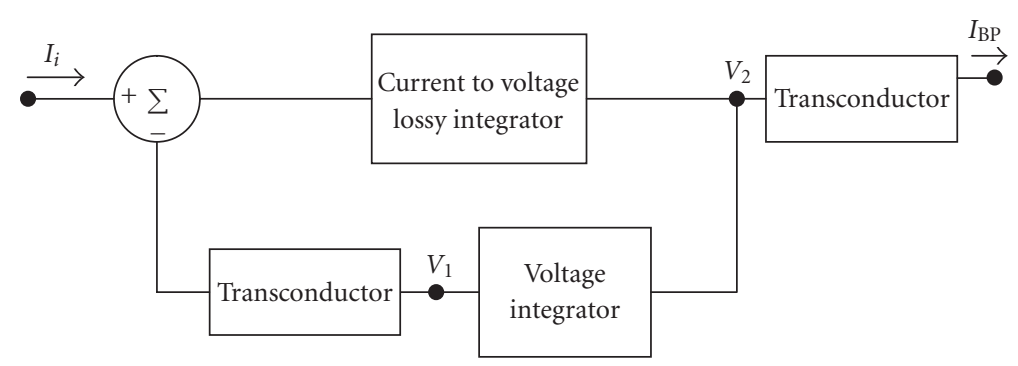

Figure 2: The block diagram of the proposed current-mode filter.

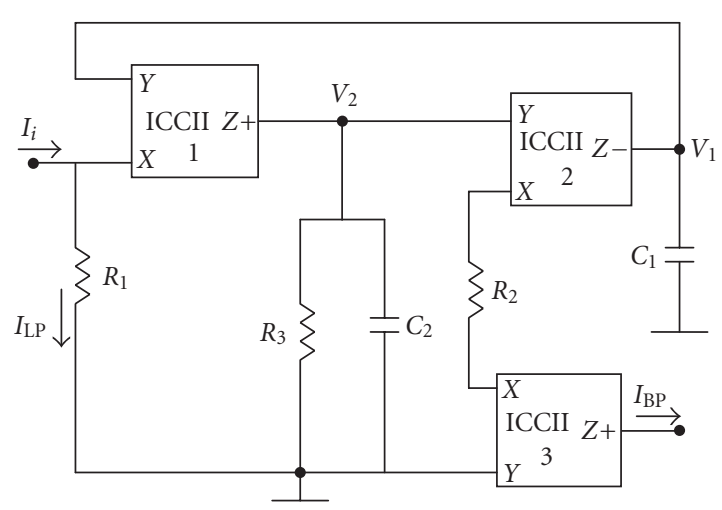

(a) Grounded C current-mode bandpass filter using three ICCII

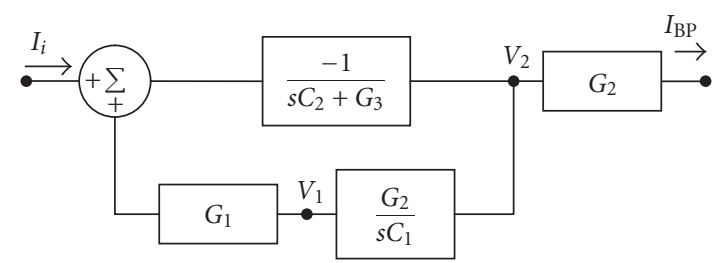

(b) Block diagram of the circuit of Figure 3(a)

FIgURE 3

Figure 5(a) represents an equivalent circuit using three ICCII+ having the block diagram of Figure 5(b) which differs from that of Figure 4(b) in three signs.

All the above equations apply also to the circuit of Figure 5(a).

It should be noted that, in all of the proposed circuits, the current in $R_{1}$ is of low-pass nature; however, to use this current, a current follower is needed.

\section{SIMULATION RESULTS}

Spice simulation results using technology SCN 05 feature size $0.5 \mu \mathrm{m}$ from MOSIS vendor: AGILENT.

The circuit of Figure 4(a) is simulated using the CMOS ICCII- of Figure 1(c) with the aspect ratios shown in Table 1 and with $V_{\mathrm{DD}}=1.5 \mathrm{~V}, V_{\mathrm{SS}}=-1.5 \mathrm{~V}$. The circuit of Figure $5(\mathrm{a})$ is simulated with the ICCII+ of Figure 1(b) with $V_{\mathrm{DD}}=1.5 \mathrm{~V}$, $V_{S S}=-1.5 \mathrm{~V}$ with aspect ratios given in Table 2 .

The two circuits are simulated to realize a bandpass filter having $f_{o}=1 \mathrm{MHz}$, and $Q=10$ and unity center frequency

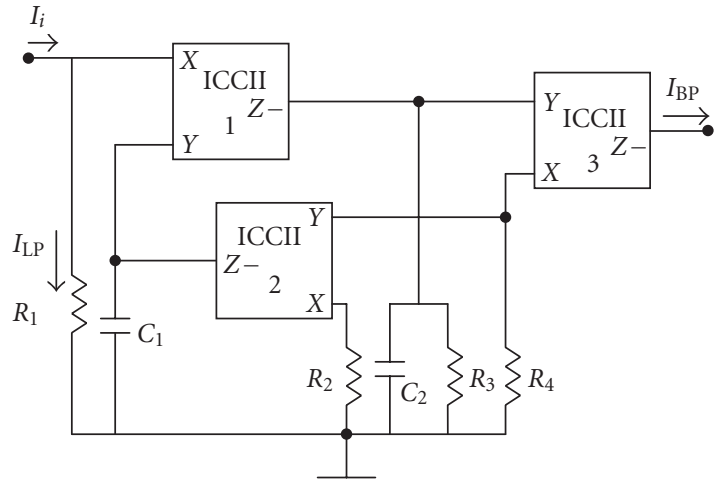

(a) Grounded $R, C$ current-mode bandpass filter using three ICCII-

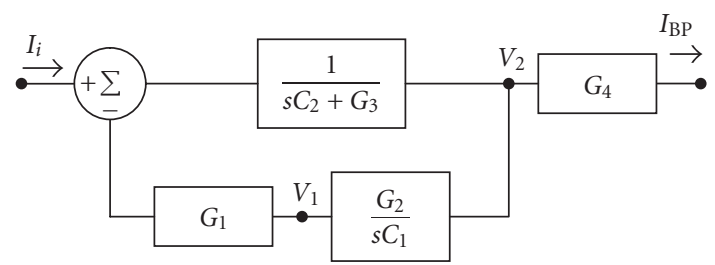

(b) Block diagram of the circuit of Figure 4(a)

Figure 4

gain. For both circuits, the design values taken are $C_{1}=C_{2}=$ $10 \mathrm{pF}, R_{1}=R_{2}=1.59 \mathrm{k} \Omega$, and $R_{3}=R_{4}=15.92 \mathrm{k} \Omega$.

Figures 6(a) and 6(b) represent the magnitude and phase characteristics for the circuits of Figures 4(a) and 5(a), respectively, together with the ideal characteristics. From the simulations it is seen that the simulated results agree well with the ideal responses.

\section{CONCLUSIONS}

New current-mode bandpass filters using three ICCII+ or three ICCII- are introduced. The circuit employs four grounded resistors and two grounded capacitors and has independent control on $Q$ and on the center frequency gain by varying a single grounded resistor. It is found that the proposed block diagram of Figure 4 cannot be realized using only three of CCII+ or three of CCII-. It is worth noting that a two CCII+, one CCII- or a two CCII-, one CCII+ bandpass current-mode filter having the same circuit topology as that of Figure 4 was given in [12]. The circuit reported 


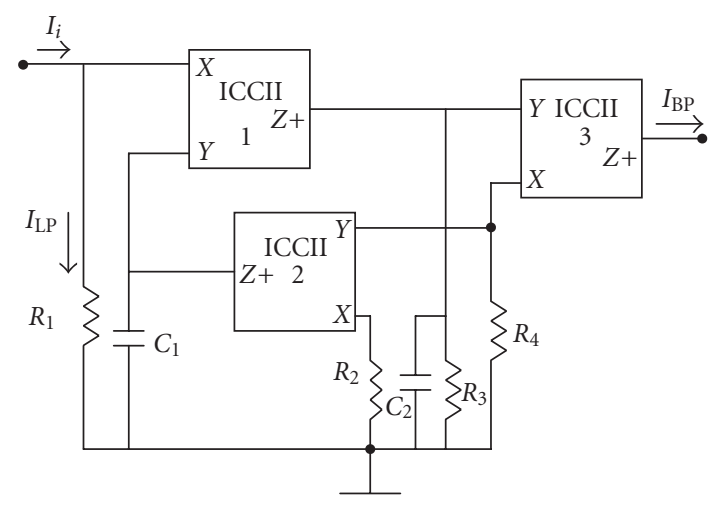

(a) Grounded $R, C$ current-mode bandpass filter using three ICCII+

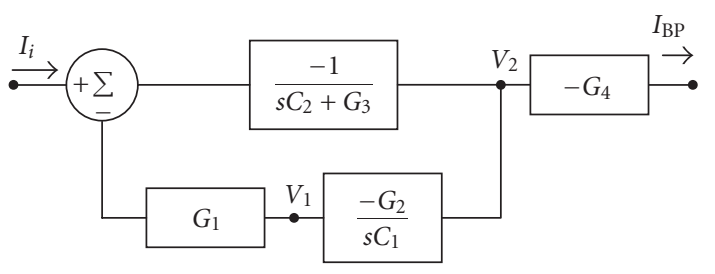

(b) Block diagram of the circuit of Figure 5(a)

Figure 5

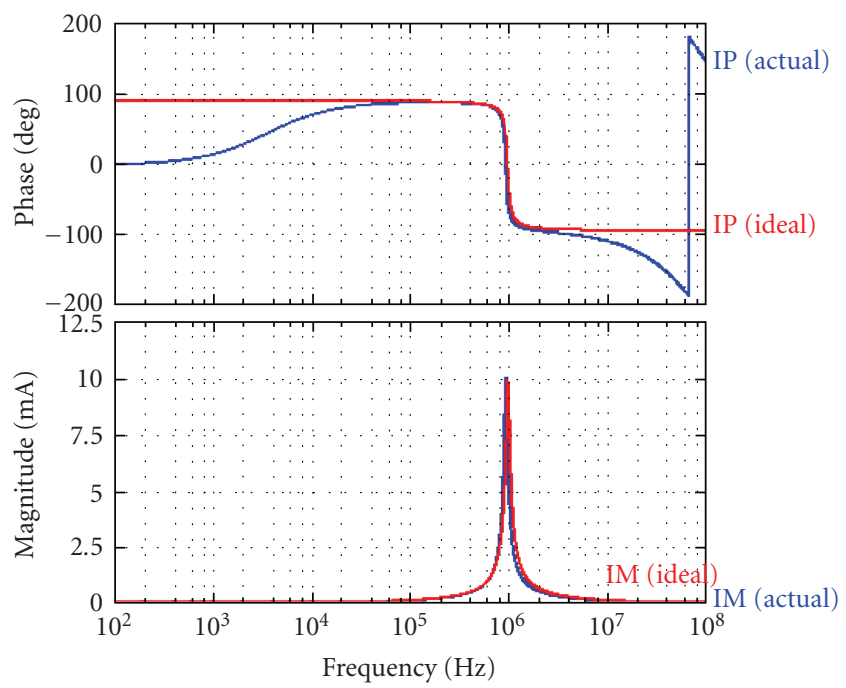

(a) Magnitude and phase characteristics of the circuit of Figure 4(a)

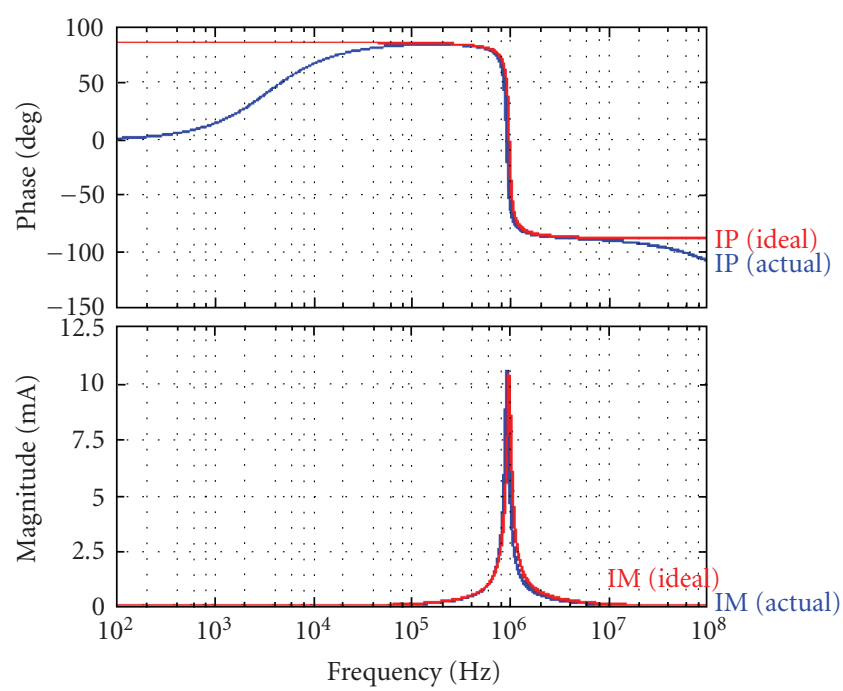

(b) Magnitude and phase characteristics of the circuit of Figure 5(a)

FIGURE 6

in [12] was generated from the Tow-Thomas $[10,11]$ circuit using a transformation method based on the adjoint network theorem [13]. It should also be noted that the recently reported current-mode bandpass filter [14] employs four ICCII blocks.

\section{REFERENCES}

[1] H. O. Elwan and A. M. Soliman, "Novel CMOS differential voltage current conveyor and its applications," IEE Proceedings: Circuits, Devices and Systems, vol. 144, no. 3, pp. 195-200, 1997.

[2] W. Chiu, S.-I. Liu, H.-W. Tsao, and J.-J. Chen, "CMOS differential difference current conveyors and their applications," IEE Proceedings: Circuits, Devices and Systems, vol. 143, no. 2, pp. 91-96, 1996.

[3] I. A. Awad and A. M. Soliman, "Inverting second generation current conveyors: the missing building blocks, CMOS realizations and applications," International Journal of Electronics, vol. 86, no. 4, pp. 413-432, 1999.
[4] A. F. Arbel and L. Goldminz, "Output stage for current-mode feedback amplifiers, theory and applications," Analog Integrated Circuits and Signal Processing, vol. 2, no. 3, pp. 243-255, 1992.

[5] K. Ikeda and Y. Tomita, "Realization of current-mode biquadratic filter using CCIIs with current followers," Electronics and Communications in Japan, vol. 77, no. 1, pp. 99-107, 1994.

[6] Y. Sun and B. Jefferies, "Current-mode biquadratic filters using dual output current conveyors," in Proceedings of the 5th IEEE International Conference on Electronics, Circuits and Systems (ICECS '98), vol. 3, pp. 135-138, Lisabon, Portugal, September 1998.

[7] C.-M. Chang, "Universal active current filter with three inputs and one output using plus-type CCIIs," Electronics Letters, vol. 33, no. 14, pp. 1207-1208, 1997.

[8] M. Higashimura, "Current mode transfer function using CCIIs with grounded passive elements," IEICE Transactions Japan, vol. E 74, pp. 1017-1018, 1991.

[9] S. Ozoguz, A. Toker, and O. Cicekoglu, "First-order allpass sections-based current-mode universal filter using ICCIIs," Electronics Letters, vol. 36, no. 17, pp. 1443-1444, 2000. 
[10] J. Tow, "Active RC filters - a state-space realization," Proceedings of the IEEE, vol. 56, no. 6, pp. 1137-1139, 1968.

[11] L. Thomas, "The Biquad-part I: some practical design considerations," IEEE Transactions on Circuits and Systems, vol. 18, no. 3, pp. 350-357, 1971.

[12] S. Celma, P. A. Martinez, and J. Sabadell, "A transformation method for equivalent infinite-gain op amp to unity-gain CCII networks," IEEE Transactions on Circuits and Systems I, vol. 43, no. 1, pp. 61-63, 1996.

[13] S. Director and R. Rohrer, "The generalized adjoint network and network sensitivities," IEEE Transactions on Circuits and Systems, vol. 16, no. 3, pp. 318-323, 1969.

[14] A. M. Soliman, "Voltage mode and current mode Tow Thomas bi-quadratic filters using inverting CCII," International Journal of Circuit Theory and Applications, vol. 35, no. 4, pp. 463-467, 2007. 

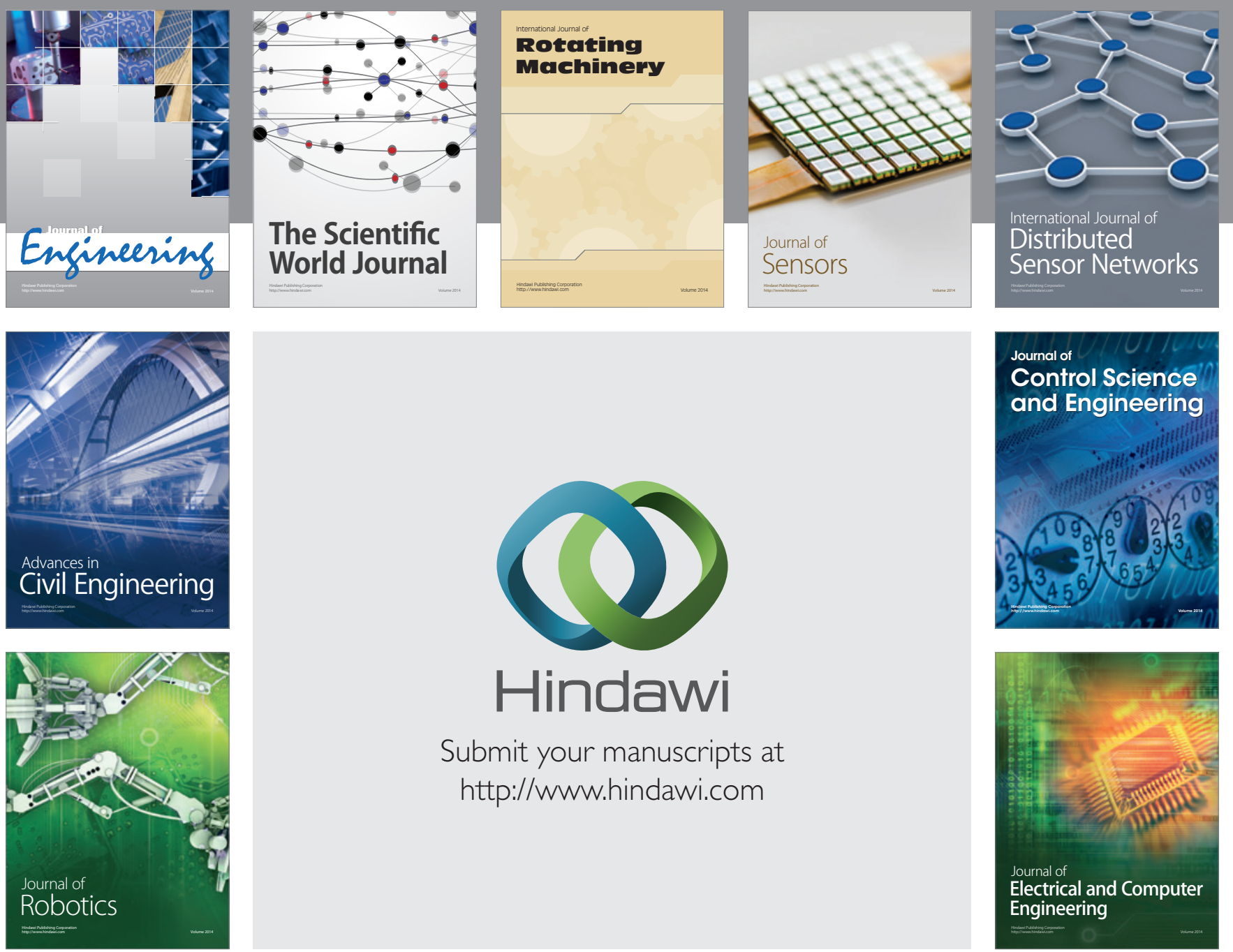

Submit your manuscripts at

http://www.hindawi.com
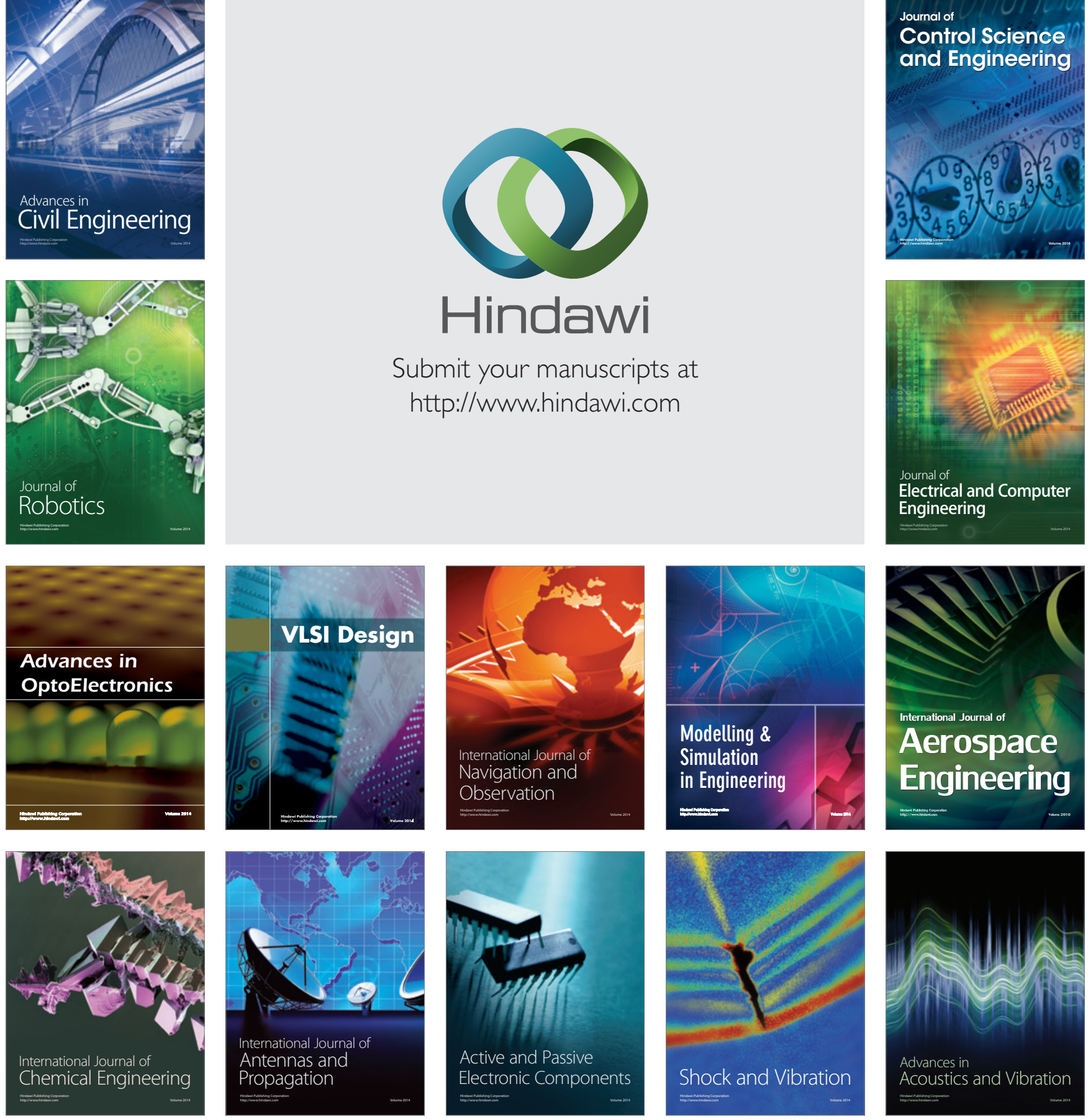